\title{
Using Fruit Size to Predict Harvest Timing of California 'Manzanillo' Olives for Ripe-black Processing
}

\author{
Louise Ferguson' \\ Department of Pomology, University of California, Davis, CA 95616
}

\author{
Hesham Gawad ${ }^{2}$ \\ University of California Kearney Agricultural Center, Parlier, CA 93648
}

G. Steven Sibbett ${ }^{3}$
Cooperative Extension, Visalia, CA 93291

Mark Freeman
Cooperative Extension, Fresno, CA 93702

James J. Hatakeda ${ }^{5}$

University of California Kearney Agricultural Center, Parlier, CA 93648

Additional index words. Olea europaea

\begin{abstract}
A stepwise multiple regression analysis, using payment by processors as the dependent variable (Y) and numerous physical and chemical characteristics as the independent variables $(X)$, demonstrated that the primary factor determining 'Manzanillo' olive (Olea europaea L.) value at harvest was size. Optimal crop value correlated strongly with the combined percentage of standard, medium, large, and extralarge olives; $R$ ' values were $0.93 * * *, 0.93 * * *$, and 0.42 (NS) in 1984, 1985, and 1986, respectively. As the harvest season progressed, increased percentages of olives within these size classifications, not weight increases of individual olives within the size categories, produced the increase in value. Individual olives within size categories maintained the same weight through the harvest season, regardless of tree crop load. The best criterion for predicting optimal harvest time "is the total percentage of standard, medium, large, and extra-large olives.
\end{abstract}

Almost all of California's 'Manzanillo' olive crop is destined for the processed, socalled "ripe-black" market. Although the name ripe-black implies a mature, tree-ripened fruit, the olives are harvested when immature. A fully tree-ripened olive is black and soft, deteriorates when processed, and is considered-a cull, suitable only for olive oil (Hartmann et al., 1959).

As the fruit is immature when harvested, reliable indicators of optimal harvest time for ripe-black processing olives are ambiguous. Previous attempts at developing harvest maturity indices for the industry have been unsuccessful and were not adopted commercially (Cruess and Pancoast, 1933; Diaz-Fernandez, 1971; Hilts and Hollingshead, 1920). The primary criterion investigated have been color (Pitman, 1930), oil content (Hartmann, 1949; Pitman, 1935), firmness (Cruess, 1934;

Received for publication 28 Aug. 1989. The cost of publishing this paper was defrayed in part by the payment of page charges. Under postal regulations,thispaper therefore must be hereby marked advertisement solely to indicate this fact.

'Extension Pomologist. Mailing address: Kearney Agricultural Center, 9246 S. Riverbend Ave., Parlier, CA 93648.

${ }^{2}$ Research Assistant.

${ }^{3}$ Tulare County Farm Advisor.

${ }^{4}$ Fresno County Farm Advisor.

${ }^{5}$ Staff Research Associate.
Cruess and Pancoast, 1933; Pitman, 1930), and fruit size and weight (Hartmann et al., 1959). Color was not a reliable indicator (Pitman, 1930), and oil content varied too greatly with environmental and edaphic factors (Hartmann et al., 1959; Hilts and Hollingshead, 1920). Hartmann et al. (1959) concluded that fruit size and firmness had the greatest potential as indicators of fruit maturity. However, in their work, firmness correlated poorly with crop value. A review of the literature indicates that size has the best potential for indicating olive maturity.

Currently, growers rely on gradual disappearance of whitish lenticels, a characteristic green to straw (yellow cast) with a purple blush color change, and presence of a milky exudate when punctured. These changes occur over 2 to 6 weeks, depending on crop size, environmental and edaphic factors, and fruit location and exposure. These qualitative harvest time indicators initially appear reasonable since the change to straw color begins after the maximal gains in fresh weight, moisture content, and dry matter (other than oil) content (Hartmann, 1949). However, in a competitive production situation, it is difficult to achieve precision with such qualitative factors. Also, there are few olive processors in California and, as such, all growers cannot deliver simultaneously. If the industry does have to develop a prorated de- livery structure in the future, those growers required to deliver at a less than optimally profitable time must be compensated.

When the olive crop is delivered to the processor, value is determined by total weight delivered, percentage composition of the crop by fruit size, and condition, primarily color development and over-ripeness. The priority of these factors in the production of olive value at harvest and how they interact has never been determined. This interaction is particularly important, as individual olive fruit size has demonstrated a strong negative correlation with crop load; the higher the yield, the smaller the fruit (Hartmann, 1952). Currently, the ripe-black processing olive market demands fruit within the middle size ranges, designated as standard $(\mathrm{S})$, medium (M), large (L), and extra-large (XL). Unlike most fresh and processed fruits, sizes larger than these produce diminishing returns due to limited demand. Because olives smaller than these popular canning sizes bring even less return, a high tonnage per hectare combined with picking costs of more than $\$ 250 /$ ton can easily result in a financial loss. An earlier study by Sibbett et al. (1986) demonstrated that delaying harvest can result in significantly higher grower returns. However, no easily measurable maturity index that can serve as a reliable predictor of optimum harvest time has been developed for field use.

Our hypothesis was that olive size, as one of the primary factors in determining olive crop value, is also the single best field-measurable characteristic for predicting the optimum harvest time.

This experiment took place in a mature (planted 1971) commercial 'Manzanillo' olive orchard, Madera County, San Joaquin Valley, Calif., spaced at $5 \times 10 \mathrm{~m} \mathrm{(237}$ trees/ha), with fogger irrigation and maintained under standard commercial production practice\}. Care was taken to select blocks with a known history of moderate cropping, as extremely lightly or heavily cropped trees could produce skewed data. The experimental design was a randomized complete block consisting of 10 blocks of nine trees each, repeated randomly within four adjacent rows and repeated with equivalent, but different, trees each year. During 1984,1985, and 1986, a single tree from each block, for a total of 10 individual replications, was harvested weekly for 9 weeks from mid-September through mid-November. Individual, total tree yield was weighed before three subsamples (10 kg each) from each tree were graded using a commercial processor to determine value. In 1985 and 1986, three additional 2.5-kg subsamples from each tree were analyzed for percent composition by size, fruit, flesh and pit weight, ratios of the same, fruit volume, fruit weight : volume ratio (density), color, firmness, flesh oil and dry matter content, $\mathrm{pH},{ }^{\circ} \mathrm{Brix}$, and fruit floatability. Fruit removal force and fruit drop on harvested trees were measured on the trees before harvest.

Fruit weight and volume were determined on the same sample and fruit weight : volume ratio was calculated from these mea- 

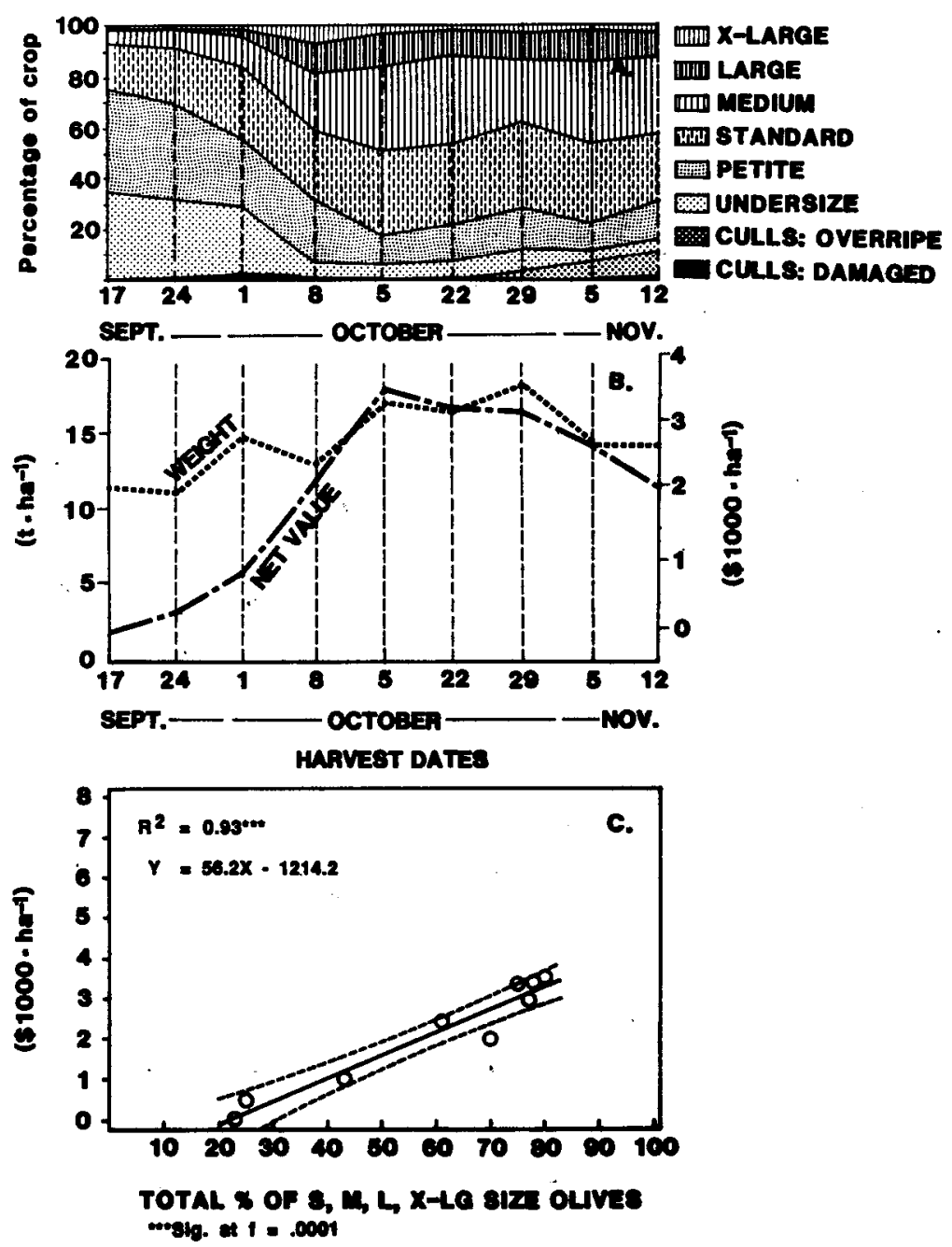

Fig. 1. (A) The changing percentages of olives of a given size through 1984 season, (B) the relationship between total yield (in tha ${ }^{-1}$ ) and net crop value (in dollars/ha) at 237 trees/ha, and (C) the relationship between total combined percentages of standard, medium, large, and extra-large olives and crop value response as net value per hectare $(\mathrm{NVH})$ given in $\$ 1000 \mathrm{~s} / \mathrm{ha}$.

surements. Pits were extracted; using a food blender during 1985 and a potato peeler during 1986, washed, air-dried at room temperature for 5 days, and the weights of 100 pits determined. Then flesh weight and the flesh : pit weight ratio was calculated.

Fruit size was determined according to the U.S. Dept. of Agriculture (USDA) and the California Dept. of Food and Agriculture (CDFA) size standards of extra-large (XL), large $(\mathrm{L})$, medium $(\mathrm{M})$, standard $(\mathrm{S})$, and petite or small $(\mathrm{P})$ (California Dept. of Food and Agriculture, 1987). Each size category is presented as the percentage of the total sample by count. Thus, the datum for each harvesting date is based on sizing 1000 fruits, i.e., 10 replicates $\mathbf{x} 100$ fruits each. During 1986 , the percentage of each size category was also determined on a weight basis, which was generally very similar to that determined by count. Therefore, only percentage by count is presented, as it is the easiest to conduct, particularly in the field.

Fruit firmness was determined using a Ametek (Lansdale, Pa.) pressure tester equipped with a 0.31 -mm-diameter flat tip. Two readings were recorded on the peeled cheeks for each fruit. Thus, firmness value for each harvesting date represents the mean of 2000 measurements.

Fruit floatability was determined by floating the fruits for 10 rein, with occasional gentle stirring, in 25 -cm-deep water in a 75 $\times 75 \times 30-\mathrm{cm}$ stainless steel container.

Flesh $\mathrm{pH}$ and ${ }^{\circ}$ Brix were determined on the juice obtained by piercing the fruits, removing the pits, blending the pulp with distilled water $(1: 1, \mathrm{w} / \mathrm{v})$, and then straining the puree through cheesecloth and centrifuging the filterate.

Flesh dry matter and oil content were determined by blending the fruits with distilled water ( 1 flesh weight : 1 water, w/v) using a Waring blender with modified blades to minimize breaking of pits. Five milliliters of the puree was then transferred to a predried glass fiber pad $(9.7 \times 11.7 \mathrm{~cm}, 0.92 \mathrm{~g})$, covered with another predried pad, and dried to a constant weight in a microwave oven (CEM Corp., Indian Trail, N. C.) for $7 \mathrm{~min}$ at $60 \%$ power, a predetermined optimum condition. The microwave oven was equipped with an analytical balance and an automatic read-out for initial and final weights, weight change, and percent dry matter of the sample. Data were adjusted for the dilution factor. Some pads were extracted with ether for oil determination from each puree of each replicate. Results of the two oil determinations were similar, and the means of the two determinations were used for the statistical analysis.

The stepwise multiple regression analysis (Little and Hills, 1978) used net value per hectare $(\mathrm{NVH})$, as determined by the processor, as the dependent variable (Y). Thus, $\mathrm{NVH}=$ (processor payment/hectare) (picking cost/hectare). The objective of using net value was to account for the effect of less-profitable olive sizes. The measured physical and chemical criteria were used as the independent value $(\mathrm{X})$ in the multiple stepwise regression analysis.

An additional 1987 trial was conducted to determine whether the weight gain of individual olives within size classes thoughout the season accounted for the increase in crop value. This trial was conducted in the same orchard on a similar block of trees as the other tests. The completely randomized experimental design consisted of 20 matched tree pairs, one lightly and one heavily cropped, randomized in six adjacent tree rows. Individual $5-\mathrm{kg}$ samples from the 40 trees were harvested weekly from mid-Sept. through mid-Nov. 1987. These individual samples were sorted according to fruit size, and 10 olives within each size class were individually weighed. The results were analyzed as an analysis of variance using the eight harvest dates as treatments. The heavily cropped and lightly cropped trees were analyzed separately.

Stepwise multiple regression revealed that the total percentage of standard, medium, large, and extra-large olives was the most precise indicator of optimal harvest time. As the independent variable $(\mathrm{X})$, this totaled percentage produced linear coefficients of correlation ( $\left.R^{2}=0.93 * * *\right)$ in both 1984 and 1985 (Figs. 1C and 2C, respectively). All the following physical and chemical characteristics measured produced weak or insignificant linear coefficients of correlation: total yield/tree, fresh individual fruit and pit weights, fresh flesh and pit weights, ratios of these, fruit volume, fruit density, color, firmness, flesh oil and dry matter content, $\mathrm{pH},{ }^{\circ} \mathrm{Brix}$, and fruit floatability (data not shown). Additionally, some of the criteria would have been unsuitable for developing an easily field-adaptable monitoring technique, unlike size determination, which is easily done in the field. These results are consistent with a related study conducted by Sibbett et al. (1986) that suggested that delaying olive harvest produced greater returns as a result of higher harvest tonnage. However, their study did not demonstrate the dynamics of this weight increase or how to predict optima.

The data given here delineate the dynamics of this increase in commercial value and suggest a way to determine the optimal harvest time. The combined percentages of 

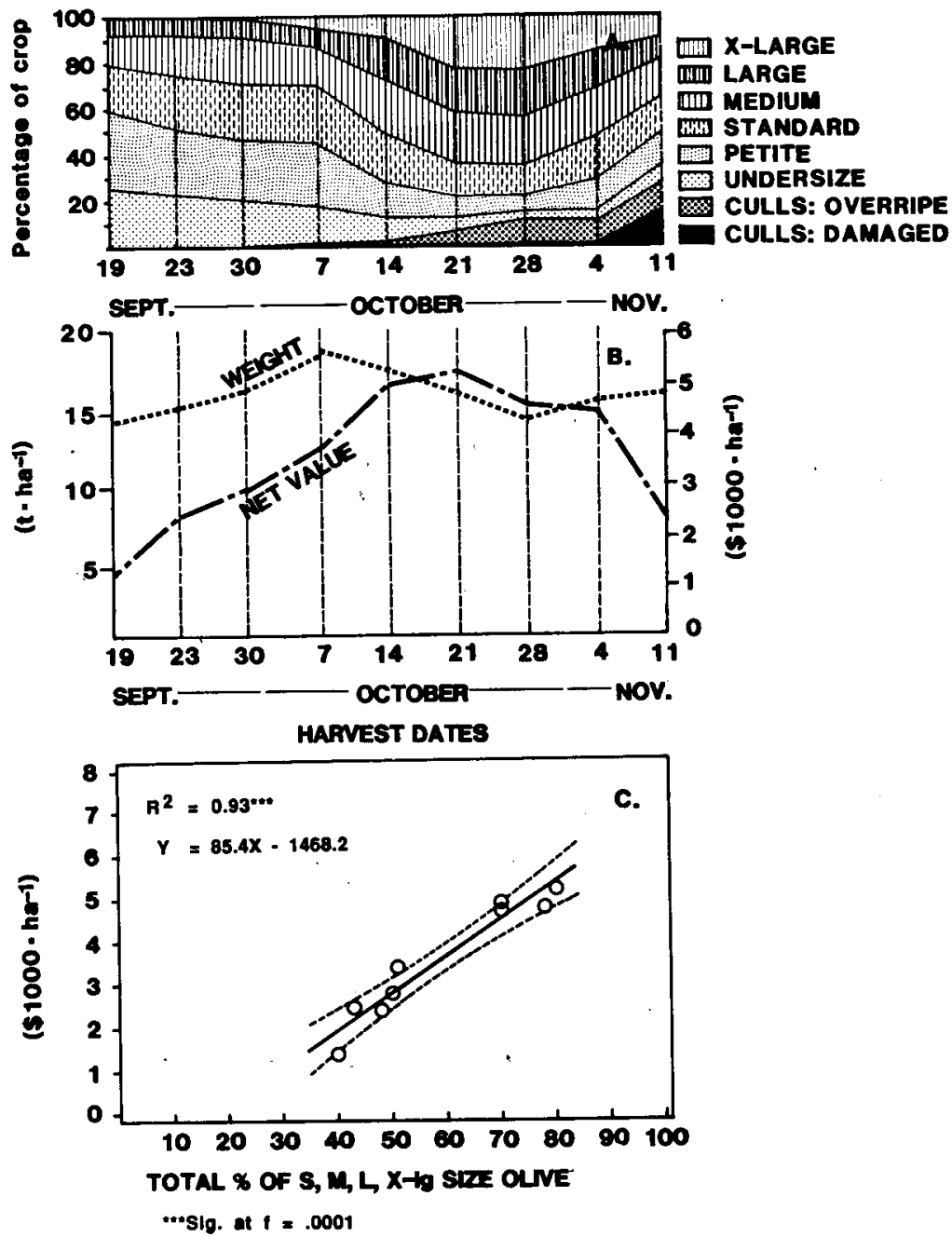

Fig. 2. (A) The changing percentages of olives of a given size through 1985 season, (B) the relationship between total yield (in $t^{\cdot h a^{-1}}$ ) and net crop value (in dollars/ha) at 237 trees/ha, and (C) the relationship between total combined percentages of standard, medium, large, and extra-large olives and crop value response as net value per hectare (NVH) given in $\$ 1000$ s/ha.

standard, medium, large, and extra-large olives (Figs. 1A and 2A) and the NVH (Figs. $\mathrm{BB}$ and $2 \mathrm{~B}$ ) increased simultaneously. Further, the relationship between yield, expressed as tons per hectare, and NVH is poor (Figs. 1B and 2B). This result confirms the hypothesis that the optimum harvest period partially depends on, and is best predicted by, the percentage composition of fruit size grades. The total tonnage increases are the result of a higher percentage of larger olives, not the result of increases in specific gravity or individual olive density, as growers commonly believe.

A weaker, nonsignificant correlation of 0.42, obtained in 1986 (data not shown), was due to lightly cropped trees with an extremely high percentage of large fruit, a later start in harvesting (22 Sept. 1986 vs. 17 Sept. 1984 and 19 Sept. 1985), daytime temperatures between 23 to $29 \mathrm{C}$, strong winds, and a malfunctioning irrigation system. This produced desiccation of the olive fruits. Thus, while olive sizes were relatively unaffected, the overall tonnage decreased and, in turn, $\mathrm{NVH}$ decreased. This problem did not negate the hypothesis that value is primarily harvest season and how to use this information to predict the optimal harvest period could provide a more accurate index of optimal harvest time than the currently used observation of olive color change.

However, because net return to the olive grower fluctuates annually due to changing harvest costs and payment by processors, the optimal harvest time cannot be calculated by entering the total percentage of standard, medium, large, and extra-large olives into the regression equations given in Figs. 1C and $2 \mathrm{C}$ because the slope and $\mathrm{Y}$-intercept change annually. Based on the results obtained by us, the test devised for the field application of this information is as follows: Starting in mid-September, collect daily samples of 100 olives randomly from around a given tree, reaching as high and low as possible. Using the olive size grades, as defined by the USDA and CDFA (California Dept. of Food and Agriculture, 1987) and generally available as perforated cards from processors, divide the 100 olives into size classifications and calculate the percentage of fruits in-each class. When the total percentage of standard, medium, large, and extra-large olives reaches $40 \%$ to $50 \%$ and is increasing by $1 \%$ to $3 \%$ daily, the optimal harvest period will commence within 1 week and last $\approx 3$ weeks.

As with all field applications, some variation exists. Tree crop load could have a great influence (Hartmann, 1952). This experiment did not specifically address how crop load affects this field technique for predicting the optimal harvest time. However, there is no reason to suspect that olives would not behave like other drupes and mature a light crop earlier than a heavy crop.

\section{Literature Cited}

California Department of Food and Agriculture. 1987. California fresh olive inspection circular. Federal-State Inspection Service; U.S. Dept. Agr., California Dept. Food Agr., Fruit and Vegetable Quality Control, Sacramento.

Cruess, W.V. 1934. The Magness pressure test andolivematurity. Proc. 13th Tech. Conf. Calif. Olive Assn. 13:16-25.

Cruess, W.V. and H.M. Pancoast. 1933. Relation between pressure test and maturity of olives. Proc. 12th Tech. Conf. Calif. Olive Assn. 127984.

Diaz-Fernandez, M.J. 1971. The olive, p. 255279. In: A.C. Hulme (cd.). The biochemistry of fruits and their products. vol. II. Academic, London.

Hartmann, H.T. 1949. Growth of the olive fruit. Proc. Amer. Soc. Hort. Sci. 54:86-94.

Hartmann, H.T. 1952. Spray thinning of olives with napthaleneacetic acid. Proc. Amer. Soc. Hort. Sci. 59:187-195.

Hartmann, H. T., M. Simone, R.H. Vaughn, and E.C. Maxie. 1959. Relation of fruit maturity at harvest to quality of black-ripe processed olives. Proc. Amer. Soc. Hort. Sci. 73:213-228.

Hilts, R.W. and R.S. Hollingshead. 1920. A chemical study of the ripening and pickling of California olives. U.S. Dept. Agr. Bur. Chem. Bul. 308. 

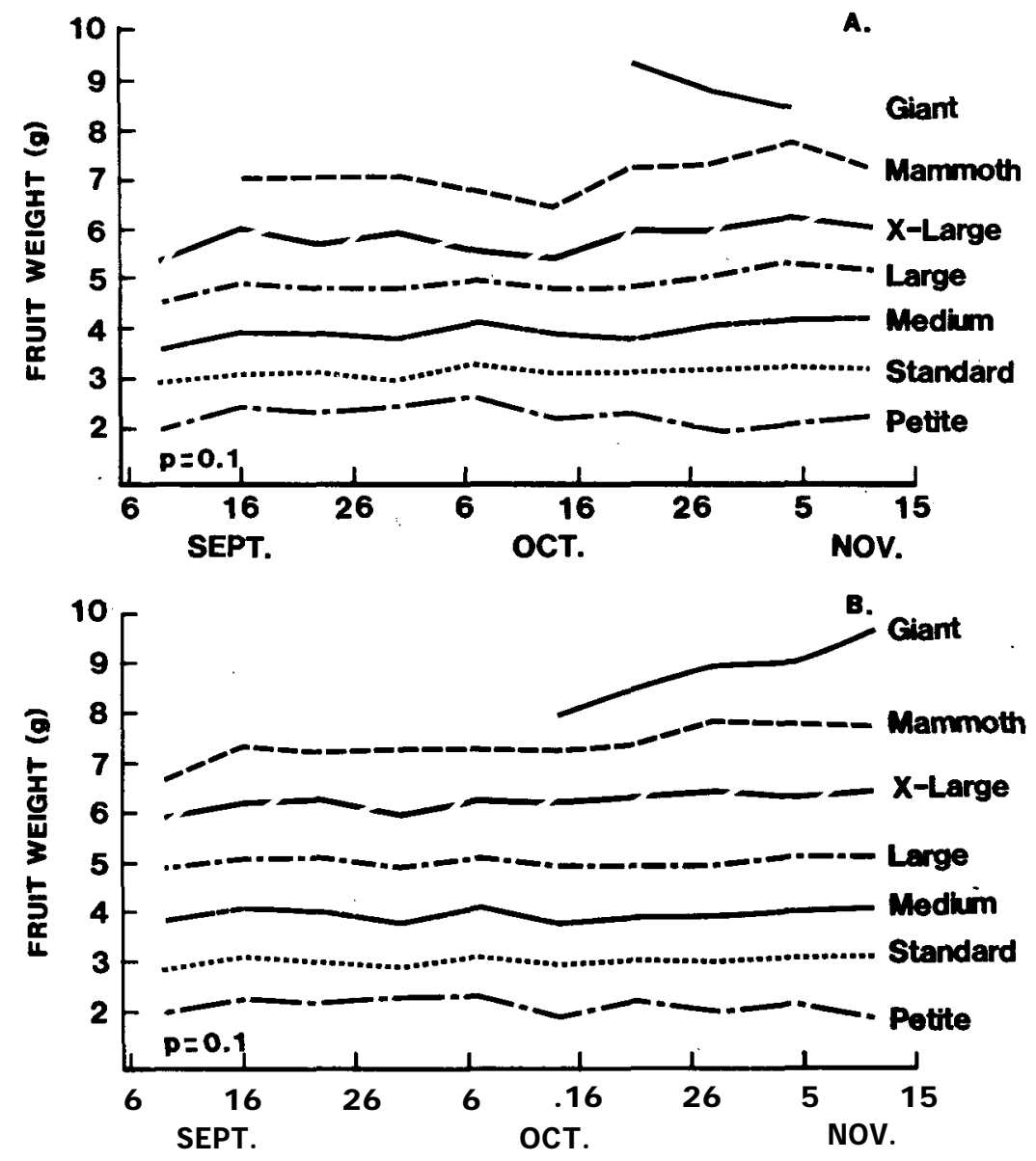

Fig. 3. Individual olive weight, within size classification, on(A) heavily cropped and (B) lightly cropped trees during the 1987 season.
Little, T.M. and F.J. Hills. 1978. Agricultural experimentation: Design and analysis. Wiley, New York.

Pitman, G. 1930. Oil content of olives in relation to various physical and visual tests of maturity. Proc. 9th Tech. Conf. Calif. Olive Assn. 9:3339.

Pitman, G. 1935. Oil content as a criterion of olive maturity. J. Assn. Offic. Agr. Chem. 18:441454.

Sibbett, G.S., M.W. Freeman, L. Ferguson, G. Welch, and D. Anderson. 1986. Timing Manzanillo olive harvest for maximum profit. Calif. Agr. 40(11, 12):19-22. 